American J. of Engineering and Applied Sciences 3 (1): 138-143, 2010

ISSN 1941-7020

(C) 2010 Science Publications

\title{
A Novel Transporting System Model for Oil Refinery
}

\author{
Razman Mat Tahar and Waleed K. Abduljabbar \\ Faculty of technology Management, University Malaysia Pahang, Kuantan, Malaysia
}

\begin{abstract}
Problem statement: Oil refineries are widely used to store various liquids and gases. Petroleum products are in high demand. Oil companies have abundant resources of petroleum products in pipelines and storage tanks. Approach: Included are storage tanks at retail gasoline station, home heating oil tanks, lubricant storage at automotive service facilities, propane tanks in all sorts of application, and oil company terminals across the world. The aim of this study is to present a model by which a decision maker should be able to choose the optimal number of tanks, tank size and truck arrival rate to maximize average total profit per week for an oil terminal operation. Results: In this study, oil terminal modeled by using a discrete event simulation program Arena for AL-Dura refinery, Baghdad, Iraq. Multifactor variance analysis is used to determine different levels of the three factors and their interactions significantly affect the terminal profit including the optimal number of tanks, size of tanks and trucks of the arrival rate to maximize total revenue on average per week. Conclusion/Recommendations: The result showed minimum cost of oil at the terminal and tanker truck fill rates and price and income structure, also predict with $90 \%$ confidence levels, a number of factors, which gives highest average total income per week
\end{abstract}

Key words: Refinery operations, petroleum, transportation, supply chain policies

\section{INTRODUCTION}

Oil terminals are widely used to store various liquids and gases such as chemicals, crude oil and natural gas. Petroleum products are in high demand for heating, manufacturing, vehicle fuel, lubricants and more. Comprehensive overview of the work associated with the optimization in oil refinery chain interestingly, a similar trend is observed for refinery modeling the supply chain. Most work on refineries food chain modeling reported in the literature only one address of the chain, such as crude logistics using discrete event simulation and optimal control (Neiro and Pinto, 2004; Reddy et al., 2004).

As recent research efforts advance in several converging areas of science and technology, how the orientation of management science in mobile is that of joint problem solving (Hughes, 1971). He sets up a network model to determine where to locate the terminals with respect to customer distribution sites. The efficient ways of loading and unloading into and out of storage tanks at oil terminals (Christofides et al., 1980). The transportation costs involved in loading and unloading these storage tanks are not investigated, additionally the article does not address the terminal profits. Simulation-based short-term scheduling of crude oil from port to refinery tanks and distillation unit, agent-based crude procurement (Cheng and Duran, 2004; Chryssolouris et al., 2005; Julka et al., 2002). External the refinery environment (Banks et al., 2002), Supply Chain Management (SCM) simulation studies at IBM and Virtual Logistics and talk about issues related to strategic and operational SCM, distributed SCM simulation and commercial packages for SCM simulation (Kleijnen, 2005). Make a distinction four types of simulation-spreadsheet simulation, system dynamics, discrete-event simulation and business games and give a literature review of the application of each type in SCM (Jung et al., 2004). Propose a simulation-based optimization computational framework for determining safety stock levels for planning and scheduling applications. They combine deterministic planning and scheduling models for optimization and a discrete-event simulation model. Their job is focused on planning and scheduling (Suresh et al., 2008). Developed Integrated Refinery In Silico (IRIS), an integrated model of all the entities in the refinery supply chain, so as to enable integrated and matched decision making.

In this study, Oil refineries model have abundant resources of petroleum products in pipelines and storage tanks. Included are storage tanks at retail gasoline station, home heating oil tanks, lubricant storage at automotive service facilities, propane tanks in

Corresponding Author: Razman Mat Tahar, Faculty of technology Management, University Malaysia Pahang, Kuantan, Malaysia 
all sorts of application and oil refineries terminals across the world. To manage these resources efficiently, it is important to have the products at the right place, in the right quantity, at the right time and at the right price. If tank managers manage supplies too tightly, they risk running low at times of crucial need, resulting in unscheduled fillings that are often expensive. The solution is to monitor supply tank levels more efficiently and cost-effectively. Various consulting groups have mainly focused on how to set up and operate oil terminals safely. There is little research on optimizing oil terminal efficiency in terms of minimizing the weekly cost of operation. With demand for oil terminals rising in the future and more emphasis laid upon how to costeffectively manage these terminals.

Related background: Most works in the literature on optimization solutions refinery with units of the plant, such as crude oil on schedule planning production, mixing gasoline, crude choices. Most of them are based on mathematical programming .The articles are discussed below in order of their generality: most general articles first, then down to the specific articles that are most closely related to the paper.

The great importance of logistics chain planning within the downstream oil industry (Sear, 1993), this study focus on transportation from refineries to customer and does not address any profitability concerns of the storage facilities.

How a real-time dispatch system can be optimized to reduce operating costs of a nation-wide fleet of petroleum tank trucks and does not address how the terminal system can be optimized to produce the highest profitability for the operation (Brown and Graves, 1981). The trade-offs among purchases, storage and service reliability decisions faced by natural gas distribution utilities (Guldmann, 1983). The gas storage has become increasingly important in managing the nations gas supplies (McVay and Spivey, 2001).

The firms have a limited number of bulk storage tanks available for intermediate storage and how an inventory stocking and replenishment system can benefit the firm (Daellenbach, 1977).

How a two-stage production system, generated by a stochastic process, can help firms optimize storage facility capacities (Bell, 1980).

Rather than focusing on a single sub-section, they attempt to model the overall refinery supply chain. Hence, IRIS enables holistic evaluation of policies, disruption management and supply chain analysis. Exploiting these capabilities of IRIS, we couple IRIS with Genetic Algorithm (GA) for our optimization purpose.

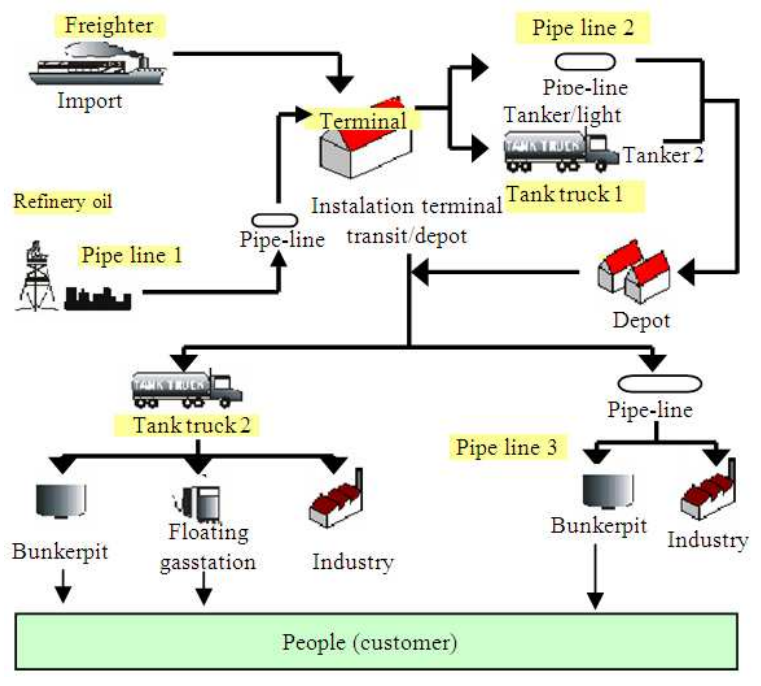

Fig. 1: The process model flowchart

System description: When oil is not required for immediate use, it may be stored in large tanks, owned by the oil and gas companies, or rented at a transport refineries oil terminal. From a major pipeline as shown in Fig. 1, the oil terminal tanks receive regular oil. Oil arrives in batches from the pipeline. It then enters into one of several tanks, each holding up to a maximum capacity. Trucks, each with a fixed capacity, arrive at a certain average rate at the terminal. After arrival to the terminal, trucks will then wait in a central queue until a tank is available for loading oil. Tank availability is defined as having oil, equal to truck capacity, available in the tank and currently, no truck is queued in front of the tank for refueling. If a truck arrives at the terminal and the number of trucks currently queued at the central queue is equal to the queue capacity then the arriving truck balks back to the truck depot.

After loading oil, trucks then depart for their destination customer location. In the event the terminal, will pass downstream and is sold as a lower grade, less profitable product, this will be referred to as discount oil. The difference between regular oil and discount oil is that a quality check is not made on the discount oil. The total cost of maintaining oil in the terminal and the associated truck costs is $\mathrm{C}$ per week. The contribution margins derived from sale of regular and discount oil is $\mathrm{R}$ per week.

All oil derivatives must be sent from the refineries to the depots. Presently, refineries have to find the depots that want to get oil. The price of the oil derivatives is determined by the oil marketing company (SOMO). On the side of purchaser (depots) they can 
buy from any refineries because the price is all the same. But on the side of the seller (refineries) the pressure is to find the nearest refinery because oil price is delivered, that is the refinery have to pay the transportation cost. The closer depots to the refineries, the better and refinery do not have to pay more.

Three factors, tank size, truck arrival rate and number of tanks, have been chosen as decision variables that can be manipulated to result in oil terminal profitability. It is suspected that there is a high correlation between these factors and the profit derived from the oil terminal operation. The number of tanks and their respective tank sizes will determine how much oil the terminal can carry, which in turn determines the total maximum revenue the oil terminal can generate through the sale of regular oil. Truck arrival rate is crucial in determining the terminal profitability, the faster the truck can move the oil from the terminal, and the more room is available for oil storage within the terminal, resulting in less oil being converted into lower grade discount oil.

\section{MATERIALS AND METHODS}

\section{The proposed method:}

Objective: The objective of this study is to maximize the average total profit per week:

$\mathrm{P}=\mathrm{R}-\mathrm{C}$

Where:

P: Total profit

R: Total contribution margin

- Revenue from sale of regular oil-cost of goods sold

- Revenue from sale of discount oil-cost of goods sold

C: Total cost

- Truck usage cost

- Truck balk cost

- Truck cost

- Lease cost

Present a model by which a decision maker, who is planning to build a new facility or expand an existing terminal, should be able to choose the optimal number of tanks, tank size and truck arrival rate to maximize profit for the oil terminal operation and minimize the weekly cost of operation.

Proposed model: Using a discrete-event simulation modeling approach, a model of the oil terminal was created in ARENA. Figure 2 shows the detail simulation model created in ARENA software and Fig. 1 shows the simplified flowchart of the model. In the model, an entity of oil is represented as a blue dot, whereas truck entities are identified by truck symbols. Both entities follow a stationary poison arrival process as depicted by the nature of the process, number of events that occur in an interval of time when the events are occurring at a constant rate. All inter-arrival times are independently and identically distributed exponential random variables with parameter as the average time between arrivals.

The simulation model has ten distinct blocks and each block is discussed separately below. The model consists of tow arrival nodes to create oil and truck arrivals. Decide nodes help determine whether or not oil should enter the terminal as regular oil or be sent downstream to be converted into a lower grade fuel, discount oil. Decide nodes are also used to determine to which tank the trucks should be sent for refueling. Find $\mathrm{J}$ node helps send oil entity to a tank with the smallest number of truck batches waiting to be loaded. A truck batch equals $2,000 \mathrm{~m}^{3}$ of oil. Process node executes the time required to fill oil into tanks. Assign nodes assign batch sizes to incoming oil entities and increase or decrease the oil work in process in the terminal to maintain a paper count of oil within the system. Hold nodes represent tanks and hold oil until a signal node sends a message to release oil into trucks. Signal nodes also send message to the remove node, which removes queued truck from the Queue node on a First-ComeFirst-Serve (FCFS). A Queue node with queue capacity holds arriving trucks in a central queue. Match nodes help match a truck to a batch of oil before sending it to the process node, which executes the time required to fill oil into trucks. Batch nodes are used to batch oil equal to the truck capacity. Several animated counters are used to help debug the model.

\section{RESULTS}

The three-factors and four levels are shown in Table 1.

Truck average Times Between Arrival (TBA) levels were carefully chosen to ensure highest profitability per week could be achieved. Using highest and lowest terminal capacity, experiments were run to determine the highest average total profit per week by varying the truck TBA. The graphs of the analysis are shown in Fig. 3 and 4.

For highest terminal capacity $\left(168,000 \mathrm{~m}^{3}\right)$, Fig. 3 shows that the highest average total profit per week occurs at truck TBA of $75 \mathrm{~min}$. Additionally, the \% truck balked, which is the percent of truck arrivals that balk out of the system, is close to zero. Therefore, truck TBA of $75 \mathrm{~min}$. was chosen as one of the levels for this factor. 


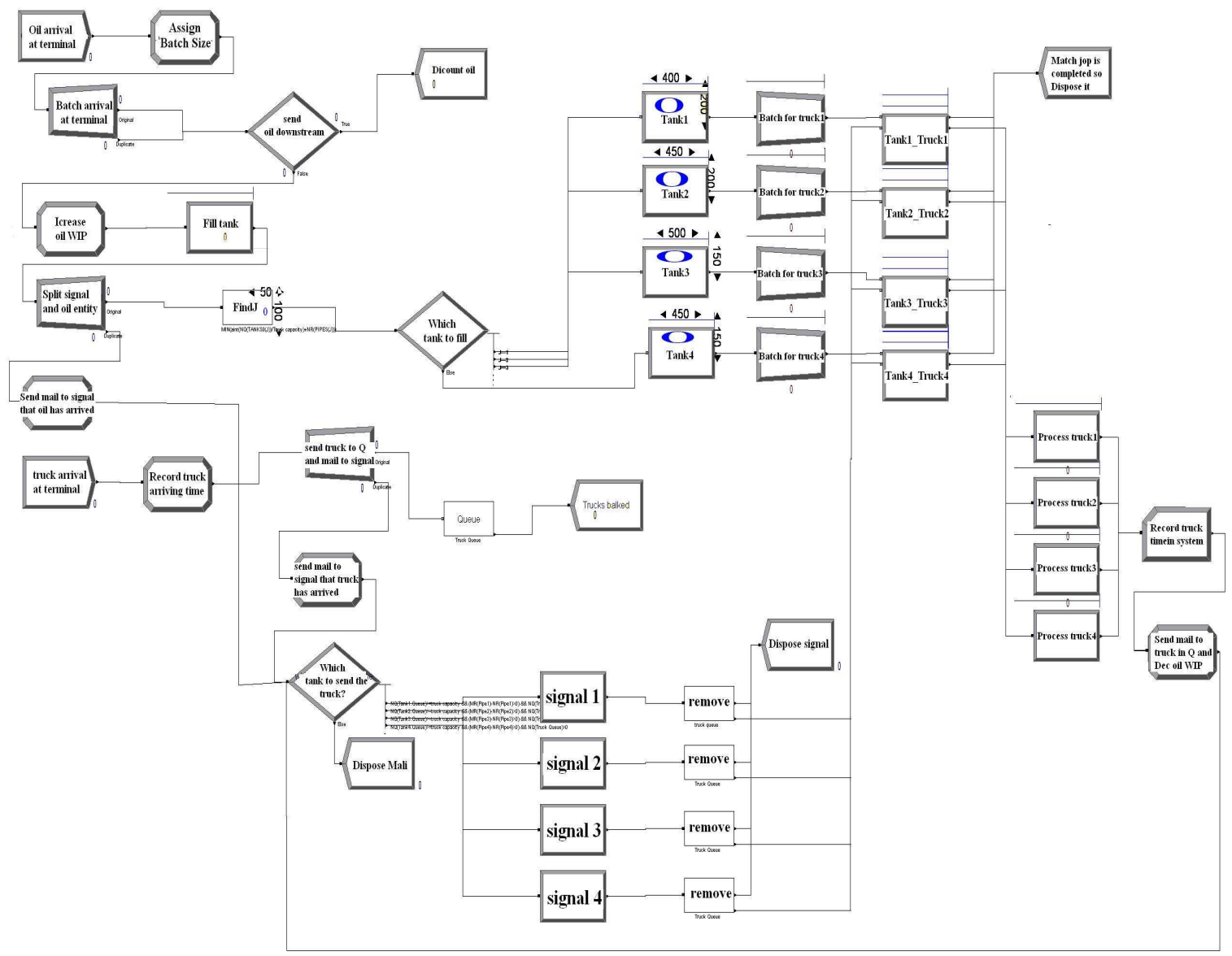

Fig. 2: Transportation model

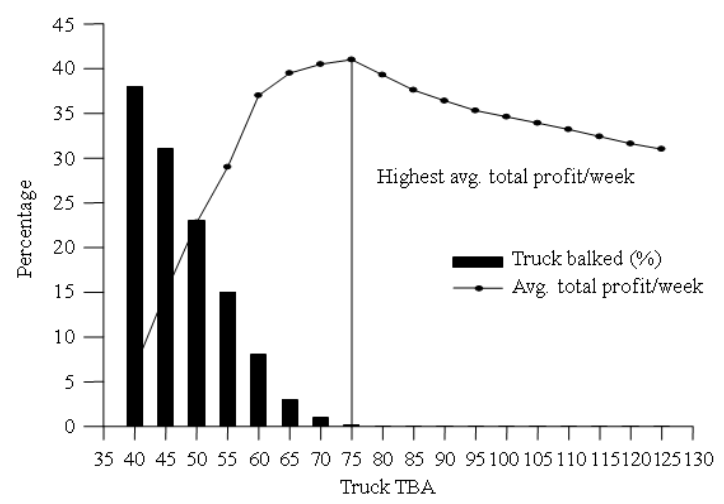

Fig. 3: Truck TBA analysis-highest terminal capacity

Table 1: Factor-level definition

\begin{tabular}{|c|c|c|c|c|}
\hline \multirow[b]{2}{*}{ Factors } & \multicolumn{4}{|c|}{ Levels } \\
\hline & 1 & 2 & 3 & 4 \\
\hline Truck-TBA (min) & 55 & 75 & 95 & 115 \\
\hline Tank size (in $1,000 \mathrm{~m}^{3}$ ) & 18 & 26 & 34 & 42 \\
\hline Number of tanks & 1 & 2 & 3 & 4 \\
\hline
\end{tabular}

For lowest terminal capacity $\left(18,000 \mathrm{~m}^{3}\right)$, Fig. 4 shows that the highest average total profit per week occurs at truck TBA of $115 \mathrm{~min}$. Therefore, truck TBA of 115 min was chosen as another level for this factor. Table 2 provides more insight into solution set.

The Maximum Average Profit (MAP) per week is if trucks did not have to wait in the system and all oil arrivals were shipped through the regular system can calculated by using the following logic:

$\mathrm{AOA} *[(\mathrm{CM})-1 / 2 *(\mathrm{CT}+\mathrm{TFT} * \mathrm{TC})]=\mathrm{MAP}$

$\mathrm{CM})-1 / 2 *(\mathrm{CT}+\mathrm{TFT} * \mathrm{TC})=$ Net profit

Where:

$\mathrm{AOA}=$ Average Oil Arrival per week)

$\mathrm{CM}=$ Contribution Margin per $1,000 \mathrm{~m}^{3}$ (regular oil)

TFT $=$ Trucks Fill Time

$\mathrm{TC}=$ Truck Cost $\mathrm{min}^{-1}$

$\mathrm{CT}=$ Cost per Truck per trip

MAP $=$ Maximum Average Profit 
Am. J. Engg. \& Applied Sci., 3 (1): 138-143, 2010

Table 2: Simulation Result of for 180 weeks, 20 weeks warm up period and 10 runs

\begin{tabular}{|c|c|c|c|c|c|c|}
\hline Avg profit/week (\$) & 18.72 & 18.74 & 18.85 & 19.02 & 19.060 & 19.78 \\
\hline Truck TBA (min) & 75.00 & 75.00 & 75.00 & 75.00 & 75.000 & 75.00 \\
\hline No. of tanks & 2.00 & 2.00 & 3.00 & 2.00 & 4.000 & 3.00 \\
\hline Tank size $\left(1,000 \mathrm{~m}^{3}\right)$ & 34.00 & 18.00 & 26.00 & 26.00 & 18.000 & 18.00 \\
\hline Terminal capacity $\left(1,000 \mathrm{~m}^{3}\right)$ & 68.00 & 36.00 & 78.00 & 52.00 & 72.000 & 54.00 \\
\hline Avg. percentage of total regular oil shipped & 83.30 & 79.50 & 85.20 & 82.10 & 85.000 & 83.60 \\
\hline Avg. percentage of total discount oil shipped & 16.70 & 20.50 & 14.80 & 17.90 & 15.000 & 16.40 \\
\hline Avg. truck balk rate $(\%)$ & 3.70 & 8.10 & 1.50 & 5.10 & 1.700 & 3.20 \\
\hline Avg. truck trip cost as a percentage of total cost & 45.29 & 46.85 & 45.63 & 46.59 & 45.950 & 47.27 \\
\hline Avg. truck in system cost as a percentage of total cost & 32.99 & 37.57 & 31.11 & 34.98 & 32.260 & 34.67 \\
\hline Avg. truck balk cost as a percentage of total cost & 1.74 & 4.12 & 0.69 & 0.49 & 0.780 & 1.58 \\
\hline Avg. truck cost as a percentage of total cost & 80.03 & 88.54 & 77.43 & 84.06 & 78.990 & 83.52 \\
\hline Avg. truck lease cost as a percentage of total cost & 19.97 & 11.46 & 22.57 & 15.94 & 21.010 & 16.48 \\
\hline Avg. truck time in system (min) & 87.42 & 96.24 & 81.80 & 90.09 & 84.255 & 88.02 \\
\hline
\end{tabular}

Table 3: Overall effectiveness sets

\begin{tabular}{lllll}
\hline $\begin{array}{l}\text { AOA } \\
\text { (week) }\end{array}$ & $\begin{array}{l}\text { Net } \\
\text { profit }\end{array}$ & Map & $\begin{array}{l}\text { Percentage } \\
\text { of min profit }\end{array}$ & $\begin{array}{l}\text { Percentage } \\
\text { of max profit }\end{array}$ \\
\hline 311.92 & 102.5 & 31.97 & 57.14 & 61.86 \\
\hline
\end{tabular}

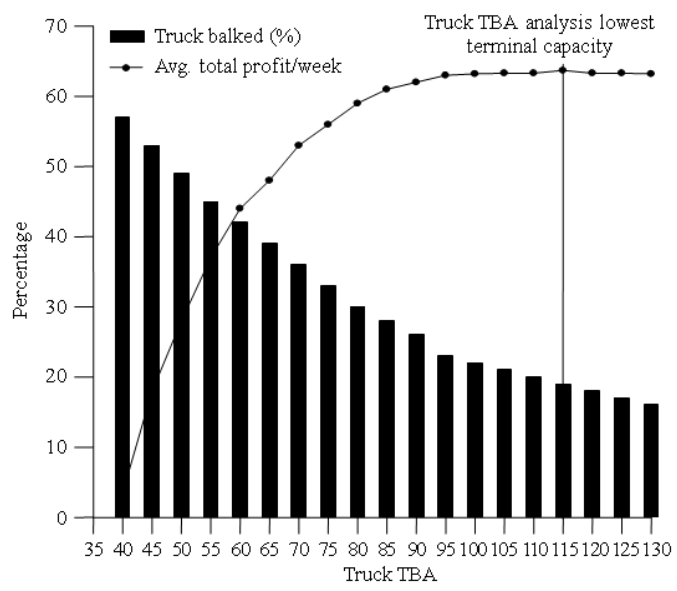

Fig. 4: Truck TBA analysis-lowest terminal capacity

By using our proposed model the min and max profit for a given set's overall effectiveness is between 57.14 and $61.86 \%$ as shown in Table 3 . The variability in the oil and truck arrival could be improved to improve the effectiveness of the model.

\section{CONCLUTION}

This research presents a new model for decision maker to able to choose the optimal number of tanks, tank size and truck arrival rate that will maximize average total profit per week for the AL- Dura refinery terminal operation. The input variables include the oil arrival rate in the terminal, the cost and contribution margin structure, the tank fill rate, truck fill rate and the oil batch size coming into the terminal. Given an oil flow rate into the oil terminal and a cost and contribution margin structure, the oil terminal profitability model is able to predict with a $90 \%$ confidence level, a group of factor-level mix, which will yield the highest average total profit per week. Management can use this model to predict the combination of truck-TBA, number of tanks and tank size to yield the highest average profit per week. The model also presents a procedure by which the decision maker can manipulate the input variables to retrieve the most profitable factor level combination.

\section{REFERENCES}

Banks, J., S. Jain, S. Buckley, P. Lendermann, M. Manivannan, 2002. Supply chain opportunities: Panel session: Opportunities for simulation in supply chain management. Winter Simulation Conference, ISBN: 0-7803-7614-5, pp: 1652-1658

Bell, P.C., 1980. A decoupling inventory problem with storage capacity constraints. Operat. Res., 28: 476-488. DOI: $10.1287 /$ opre.28.3.476

Brown, G.G. and G.W. Graves, 1981. Real-time dispatch of petroleum tank trucks. Manage. Sci., 27: 19-32. DOI: $10.1287 / \mathrm{mnsc} .27 .1 .19$

Christofides, N., A. Mingozzi and P. Toth, 1980. Dynamic loading and unloading of liquids into tanks. Operat. Res., 28: 633-649. DOI: 10.1287/opre.28.3.633

Cheng, L. and M.A. Duran, 2004. Logistics for worldwide crude oil transportation using discrete event simulation and optimal control. Comput. Chem. Eng., $\quad 28$ : $897-911 . \quad$ DOI: 10.1016/j.compchemeng.2003.09.025

Chryssolouris, G., N. Papakostas and D. Mourtzis, 2005. Refinery short-term scheduling with tank farm, inventory and distillation management: An integrated simulation-based approach. European J. Operat. $\quad$ Res., $\quad 166$ : 812-827. http://ideas.repec.org/a/eee/ejores/v166y2005i3p81 2-827.html 
Daellenbach, H.G., 1977. A model of multi-product tow-stage inventory system with limited intermediate balk storage capacity. Manage. Sci., 23: 1314-1320. http://www.jstor.org/pss/2630451

Guldmann, J.M., 1983. Supply, storage, and service reliability decisions by gas distribution utilities. Manage. $\quad$ Sci., 29: 884-906. http://www.jstor.org/pss/2631033

Hughes, H.O., 1971. Impact of management science in mobil. Operat. Res. Q., 22: 19-37. http://www.jstor.org/pss/3008292

Julka, N., I. Karimi and R. Srinivasan, 2002. Agentbased supply Chain management Part2: A refinery application. Comput. Chem. Eng., 26: 1755-1769. DOI: 10.1016/S0098-1354(02)00150-3

Jung, J.Y., G. Blau, J.F. Pekny, G.V. Reklaitis and D. Eversdyk, 2004. A simulation based optimization approach to supply chain management under demand uncertainty. Compu. Chem. Eng., 28: 2087-2106. DOI: 10.1016/j.compchemeng.2004.06.006

Kleijnen, J.P.C., 2005. Supply chain simulation tools and techniques: A survey. Int. J. Simulat. Process Model., $\quad 1$ : 82-89. DOI: 10.1504/IJSPM.2005.007116

McVay, D.A. and J.P. Spivey, 2001. Optimizing gas storage reservoir performance. Society of Petroleum Eng., 4: 173-178. DOI: 10.2118/71867PA
Neiro, S.M.S. and J.M. Pinto, 2004. A general modeling framework for the operational planning of petroleum supply chains. Comput. Chem. Eng., 28 871-896.

DOI: 10.1016/j.compchemeng.2003.09.018

Reddy, P.C.P., I.A. Karimi, R. Srinivasan, 2004. A novel solution approach for optimizing crude oil operations. AICHE J., 50: 1177-1197. http://cat.inist.fr/?aModele $=$ afficheN\&cpsidt $=1579$ 7533

Suresh, S.P., W. Li, A. Adhitya, R. Srinivasan and I.A. Karimi, 2008. Decision support for integrated refinery supply chains. 1. dynamic simulation. Comput. Chem. Eng., 32: 2767-2786. DOI: 10.1016/j.compchemeng.2007.11.006

Sear, T.N., 1993. Logistics planning in the downstream oil industry. J. Operat. Res. Society, 44: 9-17. DOI: 10.1057/jors. 1993.2 